\title{
Endocytosis of dextran and silan-coated magnetite nanoparticles and the effect of intracellular hyperthermia on human mammary carcinoma cells in vitro
}

\author{
Andreas Jordan ${ }^{\mathrm{a}, *}$, Regina Scholz ${ }^{\mathrm{a}}$, Peter Wust ${ }^{\mathrm{a}}$, Hermann Schirra ${ }^{\mathrm{b}}$, \\ Thomas Schiestel ${ }^{\mathrm{b}}$, Helmut Schmidt ${ }^{\mathrm{b}}$, Roland Felix ${ }^{\mathrm{a}}$ \\ ${ }^{a}$ Department of Radiation Oncology (WE 07), Medical Faculty of the Humboldt Universität zu Berlin, University Clinic Charité, \\ Campus Virchow-Klinikum, SFB 273, Germany \\ 'Institut für Neue Materialien (INM), Im Stadtwald, 66123 Saarbrücken, Germany
}

\begin{abstract}
To obtain more evidence for intracellular magnetic fluid hyperthermia (MFH), endocytosis and hyperthermia efficacy of silan and dextran magnetite was investigated. Differential endocytosis was observed in dependence of nanoparticle and cell type. Clonogenic survival was 3-fold lower after MFH versus waterbath hyperthermia. The selective "remote inactivation" of cancer cells by an AC magnetic field has been demonstrated in vitro.
\end{abstract}

Keywords: Endocytosis; Magnetic fluid hyperthermia; Nanoparticles; Magnetite; Cancer; Biomedical application

\section{Introduction}

Generally, hyperthermia is accomplished by heating biocompatible, coated superparamagnetic particles with an externally applied AC magnetic field (magnetic fluid hyperthermia, MFH [1]). In 1979, Gordon et al. [2] were the first to claim that some kind of intracellular hyperthermia should occur if dextran magnetite nanoparticles were taken up by cancer cells. They gave ferrofluids intra-

\footnotetext{
* Corresponding author. Tel.: + 49-30-45057073; fax: + 4930-45078979.

E-mail address: andreas.jordan@charite.de (A. Jordan)
}

venously to Sprague-Dawley rats bearing mammary carcinomas and detected cellular particle uptake by electron microscopy and iron staining of the cancerous tissue. They also showed that AC magnetic-field-induced heating occurred, however, in their in vivo experiments, it was not possible to differentiate the biological effects of interstitial (i.e. extracellular) from "real" intracellular heating.

Further experiments were done by Chan et al. in 1993 [3,4], which compared the clonogenic survival fractions of A549 human lung adenocarcinoma cells after water bath hyperthermia with the effect of MFH. In the latter case, the cells were heated in presence of dextran magnetite $(1-3 \mathrm{mg}$ ferrite $/ \mathrm{ml})$ 
but were not allowed to take up particles intracellularly. Hence, the extracellular effect of particle heating was compared with waterbath inactivation. No significant differences between both heating methods were detected. The fascinating question whether intracellular hyperthermia is really possible and which biological effect it might have in comparison to conventional extracellular heating was still not answered.

In several more comprehensive in vitro studies published by us [5-10], Chan's data were confirmed with dextran magnetite and several human carcinoma cell lines in vitro. In a second set of experiments, the cancer cells were allowed to take up particles for up to $100 \mathrm{~h}(0.8 \mathrm{mg}$ ferrite $/ \mathrm{ml}$ growth medium) until the cells were heated either in a water bath or with an externally applied AC magnetic field $(520 \mathrm{kHz}, 7-13 \mathrm{kA} / \mathrm{m})$. The amount of particles/cell was determined by measurements of the cellular iron content. Up to $1 \mathrm{pg}$ iron representing up to $10^{7}$ particles and an intracellular specific power absorption (SAR) of about $44 \mathrm{~mW} / \mathrm{ml}$ was determined in each of the cancer cells. This was expected to be large enough for cell inactivation. In contrast to these calculations and the observed large particle uptake, no additional biological effect of MFH over the waterbath heating was found. The electron microscopy images indicated that many particles had lost their shell. This was probably due to lysosomal enzymatic dextran digestion which yields overall large particle aggregation. It also decreases SAR leading to decreased cellular heating and therefore higher than expected cell survival. In conclusion, dextran coated magnetite nanoparticles were classified as not suitable for an intracellular MFH approach.

Recent studies of Bacri et al. [11] and Halbreich et al. [12] revealed some biological effects of $\mathrm{AC}$ magnetic field $(1 \mathrm{MHz}, 8 \mathrm{kA} / \mathrm{m})$ excited magnetite nanoparticles stabilized with dithiotreitol or coated with 4-hydroxytamoxifen and $\beta$-estradiol 3glycidyl ether upon macrophages, monocytic cells and MCF7 human breast cancer cells. In absence of free nanoparticles no macroscopic heating but a slight cellular inactivation of the MCF7 cells (expressing estradiol receptors) was observed using common viability tests whereas almost all monocytes remained vital. However, due to some experi- mental uncertainties, e.g. that the number of bound particles per cells was too small for heat induced inactivation and a questionable validity of viability testing used in this study to evaluate MFH efficacy, the overall conclusion of these studies are still unclear.

Intracellular magnetite nanoparticle uptake alone has been reported several times. Besides uptake into macrophages [13] or Kupffer cells of the liver [14], T-cells take up those particles by lowdensity lipoprotein (LDL) receptor-mediated endocytosis [15].

The present study was conducted to obtain more evidence for biological effects of intracellular MFH. Since it was known that dextran magnetite is not suitable for this approach, we used a silan-type coated ferrofluid preparation. It has a high enough SAR and a general biocompatibility which is comparable to dextran magnetite. In addition, silan coatings resist the enzymatic attack in lysosomes.

\section{Materials and methods}

The ferrofluids used in this study were the dextran magnetite \# P6 (Schering AG, not commercially available) and the aminosilan-coated magnetite preparation \# BU48 (INM, not commercially available). The characteristics of each ferrofluid are summarized in Table 1. Prior to biological testing, sterile filtration was performed.

Established cell lines provided by the American type culture collection (ATCC) were the normal human cerebral cortical neuronal cell line HCN-2 (ATCC CRL-10742), the human mammary carcinoma line BT20 (ATCC HTB-19) and the colonic adenocarcinoma line WiDr (ATCC CCL 218). The fibroblast line 97P599/3 was established from a normal patient punch biopsy and the line RuSiRS1 was derived from a 67-yr-old glioblastoma multiformae patient. Primary lines were cytochemically and cytologically confirmed as human and of designated cell type. All cell lines were maintained in their appropriate medium (HCN-2: DMEM with $15 \%$ FBS; BT20: BME, $1 \mathrm{mM}$ pyruvate, $5 \mathrm{ml}$ nonessential amino acids, $5 \mathrm{ml} 100 \times$ vitamins, $40 \mathrm{IE}$ insulin, $1 \mathrm{mg} / \mathrm{ml}$ glucose; WiDr: RPMI 1640 with 10\% FBS, 1 mM pyruvate; 97P599/3: medium 199, 
Table 1

\begin{tabular}{lll}
\hline Ferrofluid characteristics & \#P6 & \# BU48 \\
\hline Average particle core diameter & $3.3 \mathrm{~nm}$ & $13.1 \mathrm{~nm}$ \\
Average hydrodynamic particle diameter & $50-70 \mathrm{~nm}$ & $17 \mathrm{~nm}$ \\
Type of nanoparticle coating & Dextran & Aminosilan \\
Suspension stability as sterilized fluid & Years & Months \\
Biocompatibility & High & High \\
Formation of intracellular particle aggregates & Yes & No \\
Superparamagnetic & Yes & Yes \\
Susceptibility & $117.2 \mathrm{emu} / \mathrm{g}$ & $50-100 \mathrm{emu} / \mathrm{g}$ \\
Surface charge & Negative & Highly positive \\
Specific absorption rate (SAR) & $120 \mathrm{~mW} / \mathrm{mg} \mathrm{Fe}$ & $146 \mathrm{~mW} / \mathrm{mg} \mathrm{Fe}$ \\
\hline
\end{tabular}

15\% FBS; RuSi-RS1: BME, 10\% FBS, $1 \mathrm{mM}$ pyruvate, $5 \mathrm{ml}$ non-essential amino acids) at $37^{\circ} \mathrm{C}$, $5 \%$ carbon dioxide and $100 \%$ humidity. All cell lines underwent regular passages and were routinely checked for mycoplasma contamination.

The cells were grown in either \# P6 or \# BU48 containing medium $(0.6 \mathrm{mg}$ ferrite $/ \mathrm{ml})$ and the intracellular iron concentration determined after 0,6 , $24,48,72,144,168$ and $192 \mathrm{~h}$ using the methods and washing procedures described earlier [5].

To determine particle uptake and distribution throughout the cytoplasm, into phagosomes or lysosomes, transmission electron microscopy of selected cell preparations was done. The attachment of both particle types on the cell surface was determined by scanning electron microscopy.

Hyperthermia was performed either in a precisely controlled waterbath according to standard procedures or in a special designed AC magnetic field applicator described earlier [5]. Briefly, magnetic fluid hyperthermia was performed by inserting a small vial containing the test cells $\left(5 \times 10^{7}-1 \times 10^{8}\right.$ cell pellet) into a thermostatized bolus which in turn was inserted in a water-cooled copper coil, the AC magnetic field applicator. Before any treatment, the cells were washed ten times with phosphatebuffered saline (PBS) to remove loosely attached particles from the cell surface. The cells were either waterbath heated or AC magnetic field excited both in ferrofluid free medium at $520 \mathrm{kHz}$ and $13.2 \mathrm{kA} / \mathrm{m}$. A fluorooptic probe (Luxtron Mod. 3204, Luxtron Corp., Santa Ana, CA, USA) was used to measure the temperature inside the cell pellet. A steady-state temperature was maintained in the pellet by variation of the field strength during hyperthermia for the times indicated. Finally, clonogenic survival was calculated [16].

In principle, it is possible that individual cells take up none, a few or large amounts of ferrofluid particles during growth in ferrofluid medium in comparison to the average uptake value determined by the iron bulk measurements of cell pellets. Since determination of the iron content of each individual cell is not possible, we used a static magnetic field gradient of $50 \mathrm{mT}$ to estimate the proportion of cells which had taken up a sufficient amount of particles. We assumed that the cells, which can be attracted by such a magnetic field, contain a sufficient amount of particles for cell inactivation by $\mathrm{MFH}$. 50 microlitres of a ten times washed cell suspension grown in \# BU48 containing medium (144 h) was put into a hemacytometer chamber and a neodymium-iron-boron magnet was positioned besides the droplet. The cells not fully attracted to the magnet were assumed to contain none or very few ferrofluid particles. Using the known depth and area of the hemacytometer, the cell concentration per ml volume was calculated, as well as the fraction of "non-attractable" cells in percent. Since only BT20 cells were tested for MFH survival, these measurements were only done with this cell line.

\section{Results}

Iron uptake of malignant and normal cells was determined after growth in $0.6 \mathrm{mg} / \mathrm{ml}$ either \# P6 

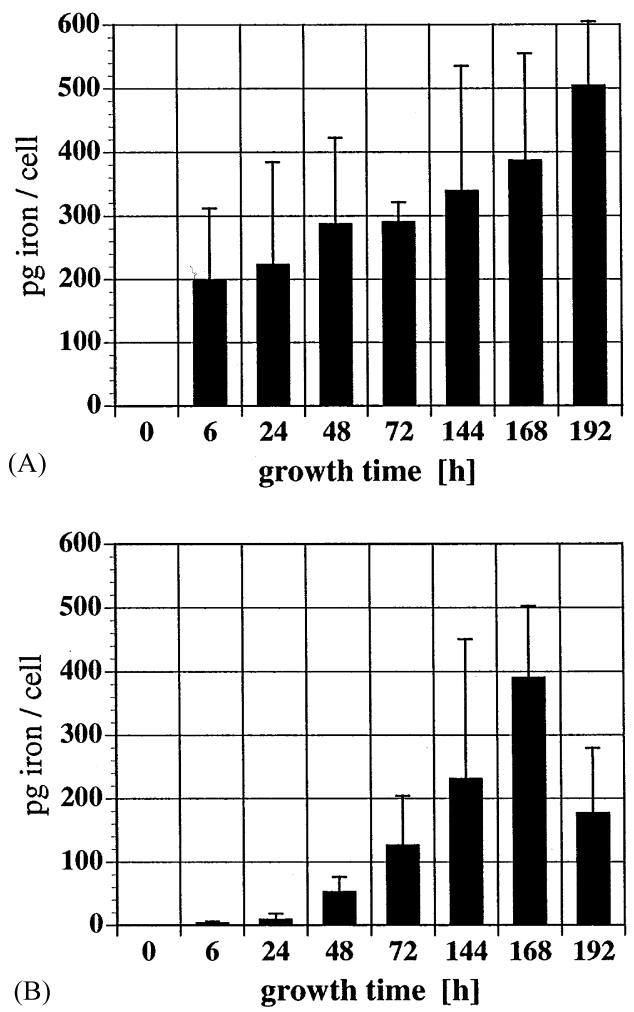

Fig. 1. \# P6 (A) and \# BU48 (B) iron uptake of normal human fibroblast cells designated as 97P599/3 in dependence on growth time.

or \# BU48 ferrite containing medium at 8 time points up to 192 h. Fig. 1A shows the iron uptake of 97P599/3 human fibroblasts grown in \# P6 containing medium in comparison to \# BU48 ferrofluid medium (Fig. 1B). \# P6 particles are rapidly taken up within $6 \mathrm{~h}$ reaching $200 \mathrm{pg}$ of iron per cell (pg/cell), which increases continuously to $500 \mathrm{pg} /$ cell after $192 \mathrm{~h}$. \# BU48 particles are taken up much more slowly, i.e. $200 \mathrm{pg} /$ cell are reached at $144 \mathrm{~h}$. Also, the peak iron content is lower at $400 \mathrm{pg} /$ cell. Fig. 2A (incubation with \# P6) and Fig. 2B (incubation with \# BU48) depict the results of iron uptake after ferrofluid incubation of WiDr human colonic adenocarcinoma cells. A much lower uptake is observed in these malignant cells for both ferrofluid preparations reaching a maximum at $50 \mathrm{pg} / \mathrm{cell}$. The strong time-dependency observed with normal fibroblasts is not present with WiDr.
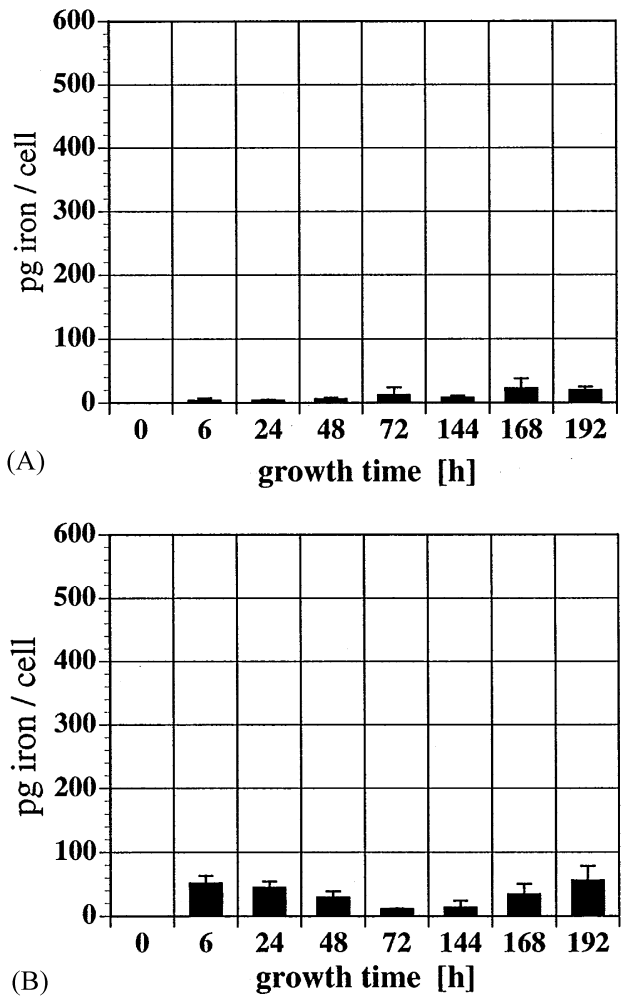

Fig. 2. \# P6 (A) and \#BU48 (B) iron uptake of malignant human colonic adenocarcinoma cells of strain WiDr in dependence on growth time.

Fig. 3A shows the iron uptake of the malignant glioma cell line RuSi-RS1 after growth in \# P6 containing medium and Fig. $3 \mathrm{~B}$ gives the results after \#BU48 incubation. In comparison to the fibroblasts, the uptake difference between both ferrofluid types is completely inverse, i.e. \# P6 is slowly and to a less extent (peak at $120 \mathrm{pg} /$ cell) taken up in comparison to a rapid and large uptake of \#BU48 (peak at $400 \mathrm{pg} / \mathrm{cell}$ ). Time dependency of \# P6 uptake is more pronounced than with \#BU48. After $6 \mathrm{~h}$, nearly maximum uptake is obtained.

Fig. 4A and Fig. 4B depict the iron uptake of normal cortical neuronal cells (HCN-2), which is the normal counterpart to the highly malignant RuSi-RS1 cells. The uptake is far lower (8-fold) in comparison to the malignant cell line and the difference between both ferrofluids is rather marginal (both concentrations peak at about $50 \mathrm{pg} / \mathrm{cell}$ ). 

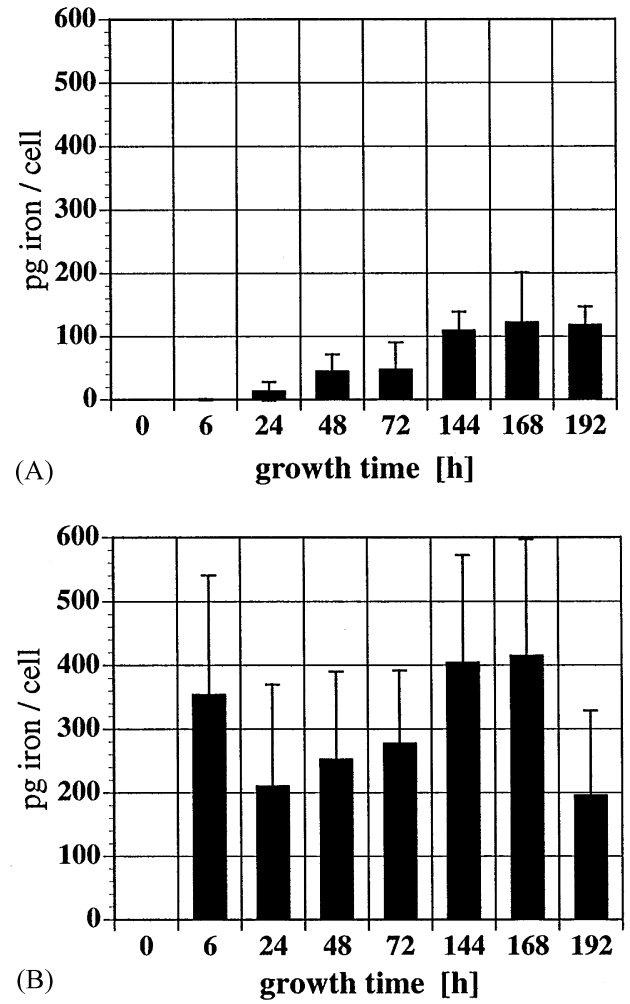

Fig. 3. \# P6 (A) and \# BU48 (B) iron uptake of malignant human glioma cells designated as RuSi-RS1 in dependence on growth time.

These quantitative results are expressively confirmed by observations of the vital culture in ferrofluid containing medium in comparison to normal medium. Fig. 5A shows a phase-contrast light microscopic picture $(100 \mathrm{x})$ of a normal culture of $\mathrm{HCN}-2$ in comparison to the malignant counterpart RuSi-RS1 shown in Fig. 6A. Whereas \# P6 incubation $(144 \mathrm{~h}, 0.6 \mathrm{mg} / \mathrm{ml})$ does not alter pigmentation or viability of both cell types (except a slight disposition to detachment from the surface, Fig. 5B and Fig. 6B), incubation with \#BU48 yields for the same time period and ferrite concentration a slight cell pigmentation with $\mathrm{HCN}-2$ (Fig. 5C). This happens to an even larger extent with the malignant line RuSi-RS1 (Fig. 6C). These observations are consistent with the iron uptake data, which also indicated a large uptake of \# BU48 into RuSi-RS1, but not into HCN-2 and a rather low \# P6 uptake with both cell types.
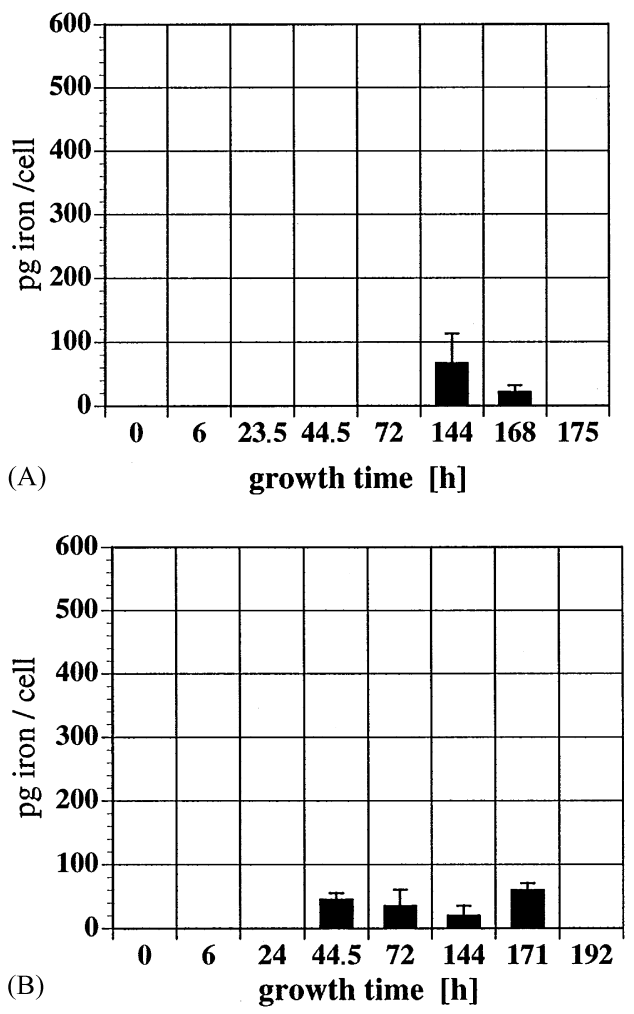

Fig. 4. \# P6 (A) and \#BU48 (B) iron uptake of the normal human cerebral cortical neuronal cell line $\mathrm{HCN}-2$ in dependence on growth time.

Scanning electron microscopy (SEM) of the $\mathrm{HCN}-2$ cell surface indicates large differences of particle attachment between \# P6 and \#BU48. Fig. 7A shows the normal surface of $\mathrm{HCN}-2$, Fig. 7B depicts the surface of $\mathrm{HCN}-2$ after $72 \mathrm{~h}$ at $0.6 \mathrm{mg} / \mathrm{ml}$ growth in \# P6 containing medium. For the same time period and concentration in Fig. 7C the cell surface after \#BU48 incubation is shown. In Fig. 7B \# P6, particles are scattered as single particles all over the cell membrane and are few in number. In Fig. 7C, the \#BU48 particles are attached to the cell surface in large fields and are greater in number. In comparison to these results with normal cells, Fig. 8A (normal culture), Fig. 8B and Fig. 8C indicate particle attachment to RuSi-RS1 cells. In agreement with the iron uptake data, many more \# BU48 particles (Fig. 8C) are attached in comparison to \# P6. The white arrows indicate 

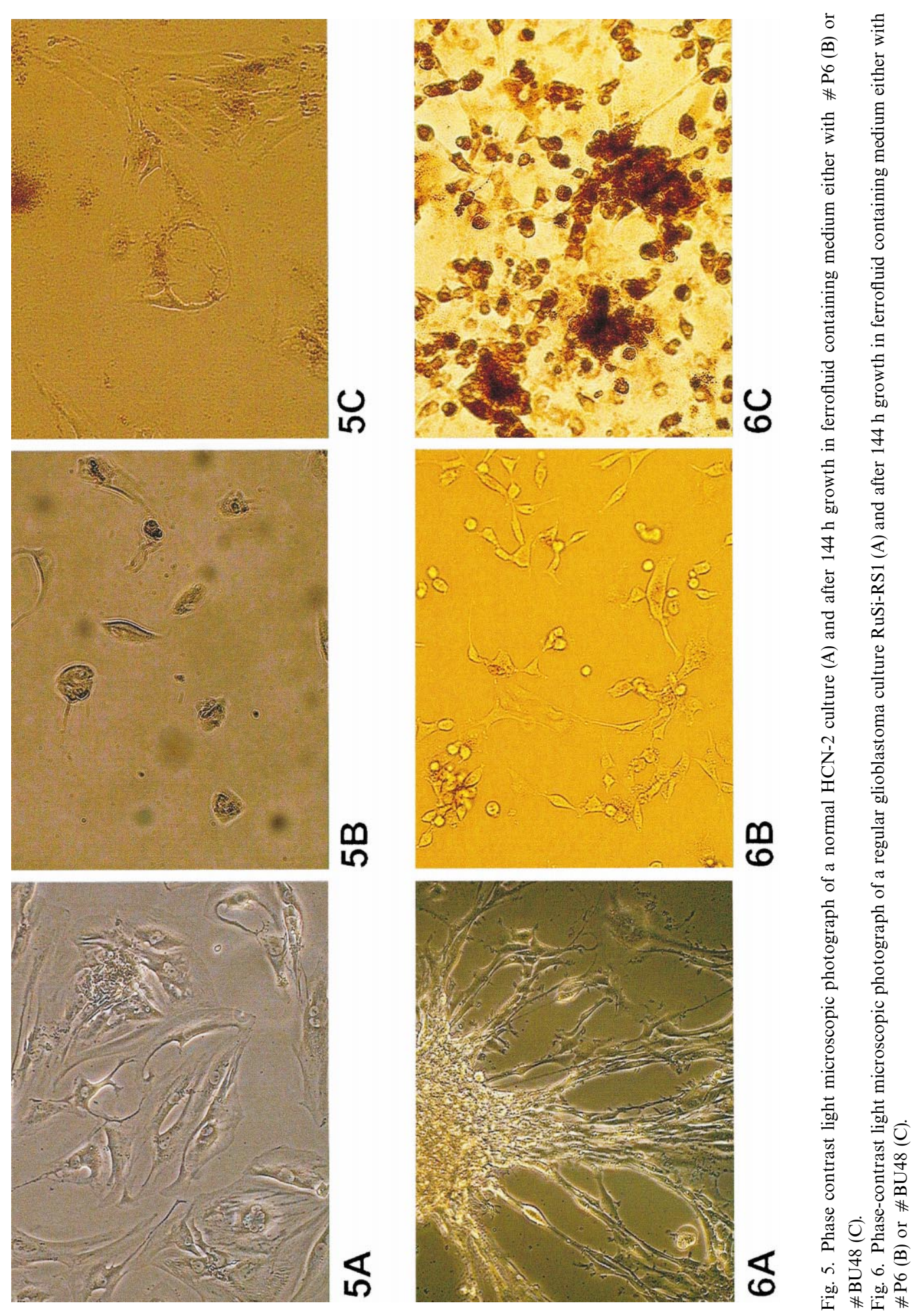

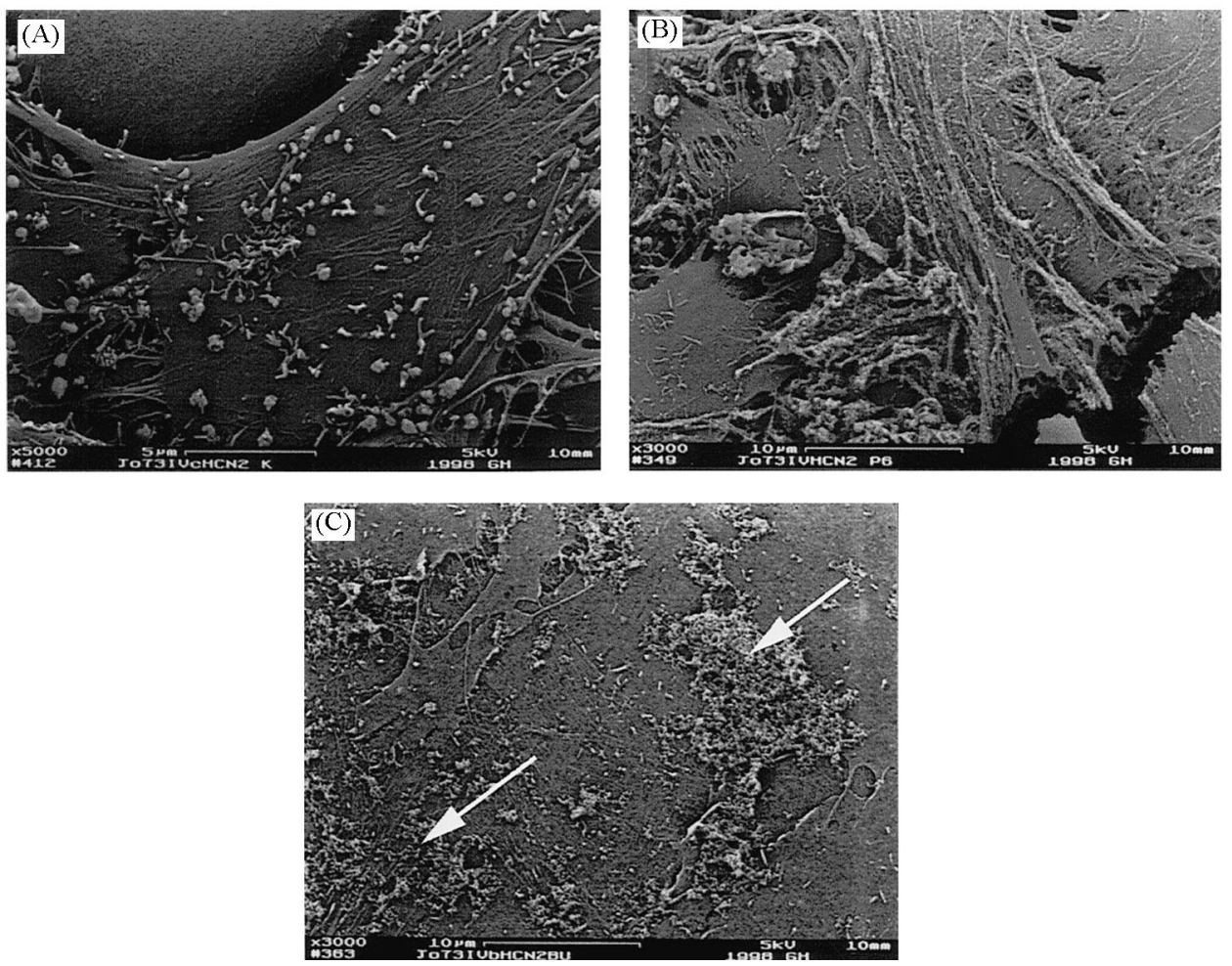

Fig. 7. Scanning electron microscopic (SEM) picture of a normal HCN-2 cell (A) and after $72 \mathrm{~h}$ growth in ferrofluid containing medium either with \# P6 (B) or \# BU48 (C). The white arrows indicate particle fields or single aggregates of the ferrofluid preparations.

particle fields or single aggregates of the ferrofluid preparations.

Since particle cell surface attachment is not necessarily an indicator for particle uptake, transmission electron microscopy (TEM) was performed to characterize particle uptake into the cell cytoplasm. Fig. 9A shows \# P6 particles with $\mathrm{HCN}-2$ cells and Fig. 9B an analogous preparation with \#BU48 after a $72 \mathrm{~h}$ incubation at $0.6 \mathrm{mg} / \mathrm{ml}$ ferrofluid concentration. In Fig. 9A nearly all visible \# P6 particles are outside the cell (black arrows) and have formed large aggregates, which may have been formed during the preparation procedures for electron microscopy and thus are not necessarily present in the living culture. In Fig. 9B it is difficult to decide whether some particles have entered the cytoplasm, but again most of the particles are outside the cell. The circular shaped body besides the long healthy HCN-2 cell is most probably detached debris of a non-viable cell. Fig. 10A and Fig. 10B give an impression of the huge particle uptake into the RuSi-RS1 primary glioma cells after $72 \mathrm{~h}$ \# P6 $(0.6 \mathrm{mg} / \mathrm{ml})$ incubation (Fig. $10 \mathrm{~A})$ or within \# BU48 containing medium of the same concentration (Fig. 10B). The white arrows indicate extended phagosomes containing a large number of particles of both ferrofluid types. The \# P6 particles appear often to occur in aggregates, probably with lost or partially degraded dextran shells, whereas almost all \# BU48 particles remain clearly separated.

In order to test the biological effect of these intracellular particles, magnetic fluid hyperthermia was performed with \#BU48 pre-incubated cells $(144 \mathrm{~h}, 0.6 \mathrm{mg} / \mathrm{ml})$ after ten washes to completely remove loosely attached and free particles in the medium. For these experiments we used the established mammary carcinoma cell line BT20 since they had the capability to form distinct and reproducible colonies as required for the clinically relevant clonogenic assay. 

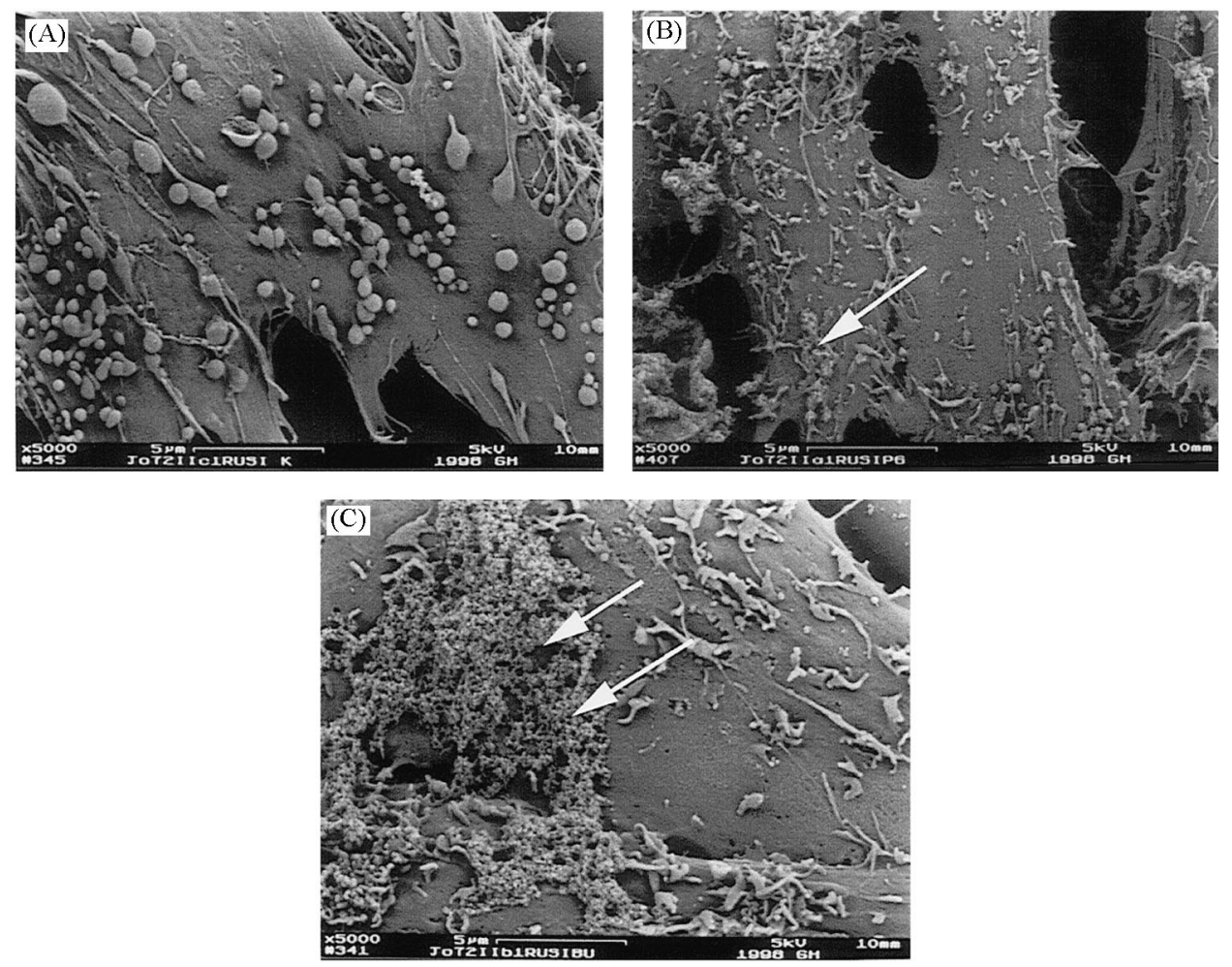

Fig. 8. Scanning electron microscopic (SEM) picture of untreated RuSi-RS1 cells (A) and after $72 \mathrm{~h}$ growth in ferrofluid containing medium either with \# P6 (B) or \# BU48 (C).

BT20 exhibits a quite similar \#BU48 uptake (data not shown) as RuSi-RS1, but does form colonies with a plating efficiency of more than 0.8 . Fig. 11A shows adherent BT20 cells with many phagosomes containing large amounts of \# BU48 particles. Fig. 11B indicates a BT20 cell which has been enzymatically detached from the surface of the culture flask (trypsinization) prior to $\mathrm{MFH}$ treatment, i.e. centrifugation and cell pellet formation. A huge amount of ferrofluid particle containing phagosomes or lysosomes can be seen in the circular-shaped cell.

Fig. 12A shows the survival curves after intracellular MFH versus waterbath hyperthermia of particle containing BT20 cells (pre-incubation $144 \mathrm{~h}$ at $0.6 \mathrm{mg} / \mathrm{ml}$ ) treated in ferrofluid-free medium at a steady state temperature inside the cell pellet of $43^{\circ} \mathrm{C}$. Waterbath hyperthermia yields a typical dose response curve in dependence on heating time, which can be normally described with the multi- target, single-hit model [16]. In contrast, the MFH curve shows a 3 -fold decrease $(40 \mathrm{~min}$ ) of the survival fraction in comparison to the very similar waterbath hyperthermia. This survival difference is pronounced at the clinically most important low thermal doses, i.e. 10-60 min treatment time at $43^{\circ} \mathrm{C}$, but turns to nearly zero at $120 \mathrm{~min}$. Fig. $12 \mathrm{~B}$ shows the results of a similar experiment at $45^{\circ} \mathrm{C}$. The survival differences between magnetic fluid and waterbath hyperthermia are similar at maximum (3-fold) but tend to zero much earlier at $25 \mathrm{~min}$ treatment time in comparison to $43^{\circ} \mathrm{C}$ at $120 \mathrm{~min}$.

Fig. $11 \mathrm{~B}$ is the TEM picture of a BT20 cell after $10 \mathrm{~min} \mathrm{MFH}$ at $43^{\circ} \mathrm{C}$. In comparison to Fig. $11 \mathrm{~A}$ (no heating, growth in ferrofluid containing medium only) a slight vacuolization process is discernable within the phagosomes or lysosomes containing the \#BU48 ferrofluid particles. This can be seen in the micrograph by the appearance of more or less white edges between the particle 


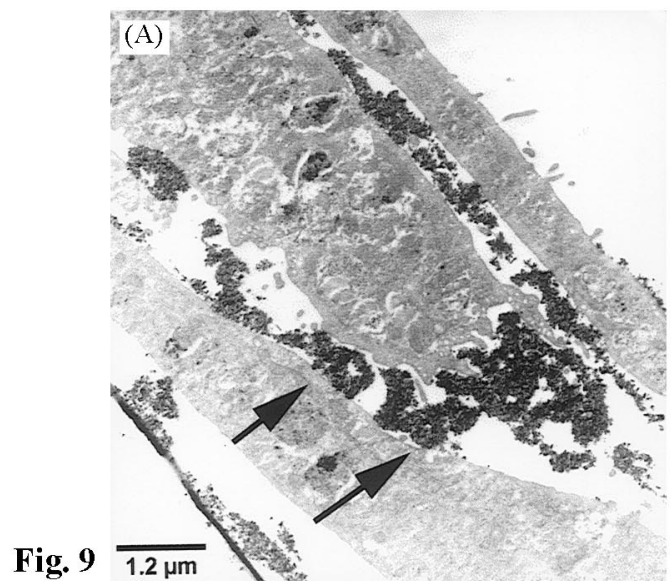

(B)
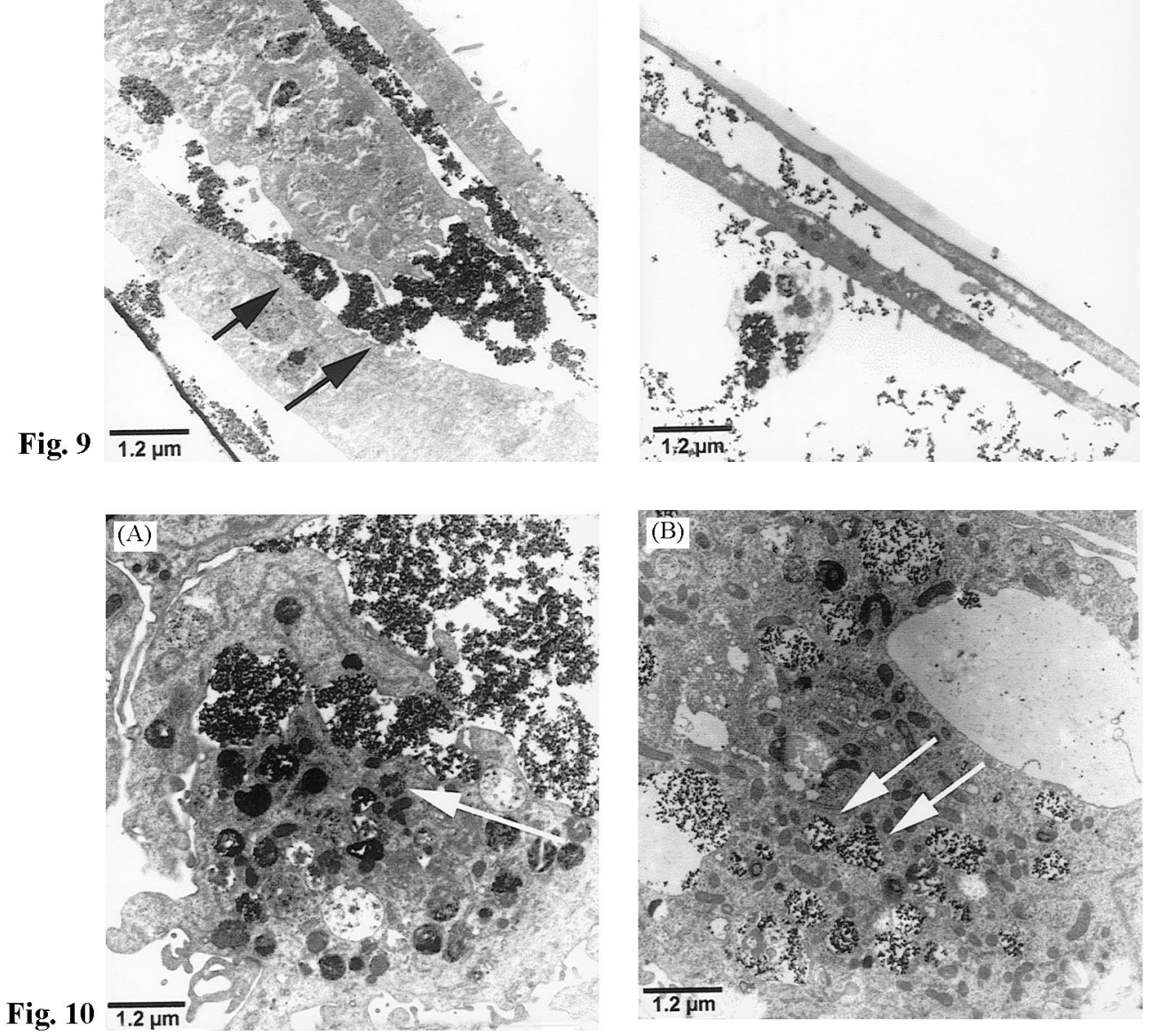

Fig. 9. Transmission electron microscopic (TEM) picture of HCN-2 cells $72 \mathrm{~h}$ growth in either \# P6 (0.6 mg/ml) (A) or \# BU48 $(0.6 \mathrm{mg} / \mathrm{ml})(B)$ containing medium.

Fig. 10. Transmission electron microscopic (TEM) picture of RuSi-RS1 primary glioma cells $72 \mathrm{~h}$ grown in either \# P6 (0.6 mg/ml) (A) or \# BU48 $(0.6 \mathrm{mg} / \mathrm{ml})(\mathrm{B})$ containing medium.

accumulations and the endogenic phagosomal or lysosomal membranes. This process turns to massive cell necrosis when the thermal dose is increased. Fig. $11 \mathrm{C}$ shows a BT20 cell after $60 \mathrm{~min}, 43^{\circ} \mathrm{C}$ magnetic fluid hyperthermia yielding a survival fraction of only $10 \%$ (Fig. 12A).

Fig. 11D illustrates that parent cells, which have taken up large amounts of \# BU48 ferrofluid particles, cannot get rid of them. The two daughter cells receive nearly $50 \%$ of the ferrofluid parent mass, so that the "magnetic label" in dividing cells will be diluted exponentially depending on population doubling time.
If ferrofluid \#BU48 $144 \mathrm{~h}$ pre-incubated BT20 cells are trypsinized and the cell suspension is exposed to a $50 \mathrm{mT}$ static magnetic field gradient a cell portion of $11.2 \pm 2.1 \%$ does not move, i.e. contains very few or no particles.

\section{Discussion}

Differential endocytosis of the dextran magnetite \# P6 and the silan coated magnetite \# BU48 was investigated with human malignant (WiDr, BT20, RuSi) and normal (97P599/3, HCN-2) cells in vitro. 

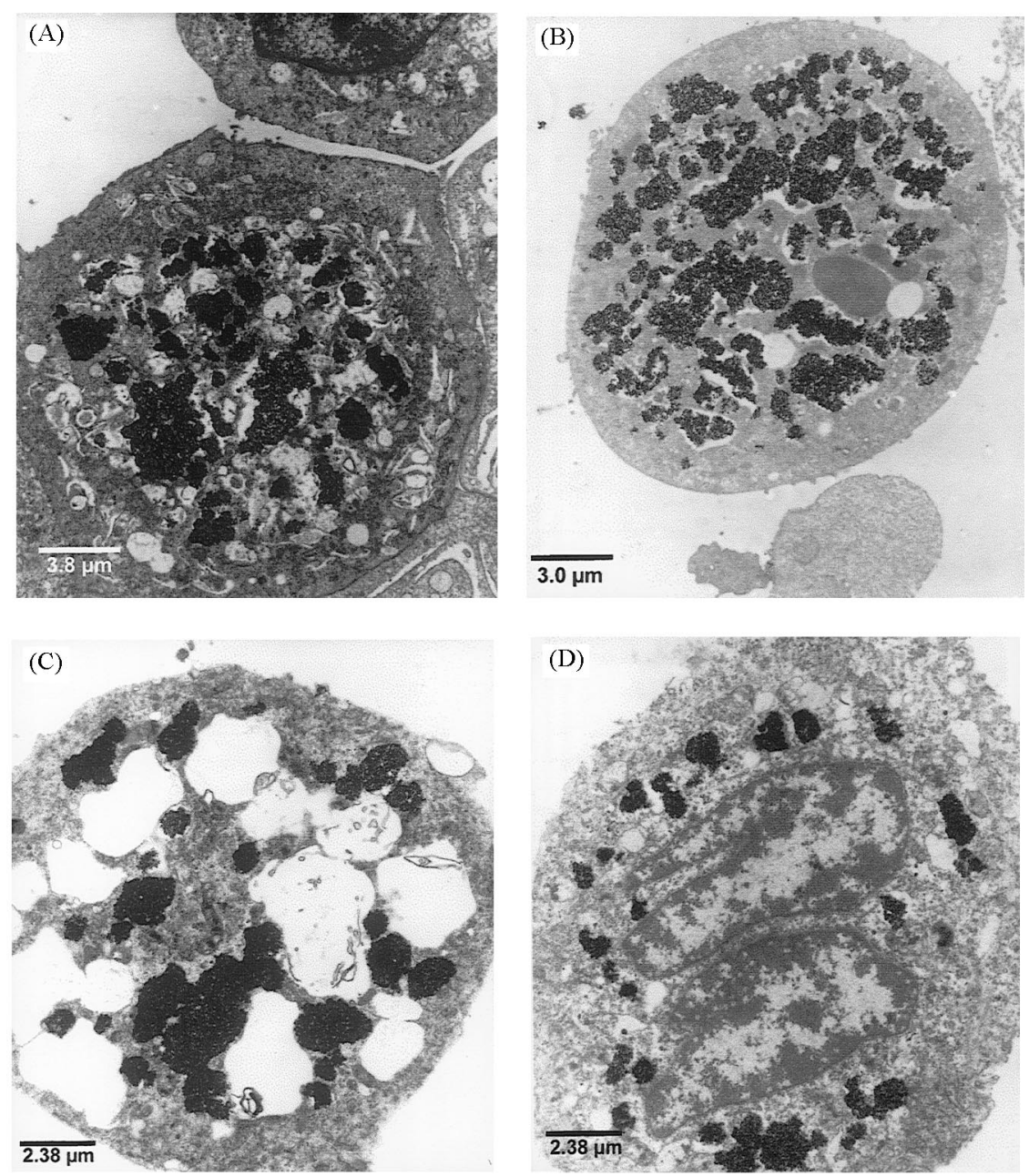

Fig. 11. Transmission electron microscopic (TEM) picture of adherent human mammary carcinoma cells of strain BT20: (A) after 144 h growth in \# BU48 (0.6 mg/ml) containing medium; (B) BT20 cell in suspension grown under the same conditions; (C) after 60 min, $43^{\circ} \mathrm{C}$ magnetic fluid hyperthermia yielding a survival fraction of only $10 \%$. (D) During nucleus and cell division, particle containing phagosomes are equal distributed to both daughter cells.

Normal fibroblasts take up 200-fold \# P6 iron within the first $6 \mathrm{~h}$ whereas \# BU48 is taken up far less within the first $48 \mathrm{~h}$. The malignant lines WiDr and RuSi-RS1 have a completely different uptake behavior. RuSi-RS1 exibits a large and very fast uptake of \#BU48 in contrast to a low and slow uptake of \# P6. WiDr takes up only low amounts of either \# P6 or \# BU48 with no time dependency, which is quite similar to the glioma line $\mathrm{HCN}-2$ (the normal counterpart of RuSi-RS1). In conclusion, it is obvious, that different surface structures can be used to induce differential endocytosis at least in vitro. Since both particle surface structures do not have ligands of biological specificity, the process of unspecific endocytosis according to the "coated pit" internalization process is the most probable one. A huge number of particles are taken up so quickly, they cannot be internalized by any specific receptors. In contrast to well known biologically specific internalization processes, little is known about the extent and mechanisms of unspecific endocytosis especially of cancer cells. Most of our 

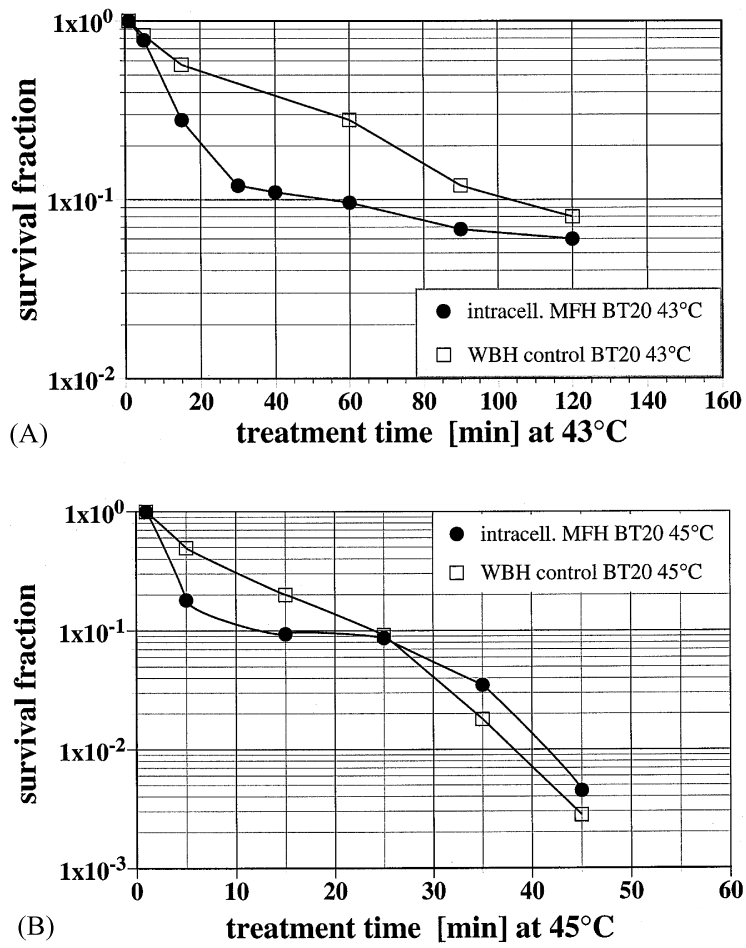

Fig. 12. (A) Intracellular MFH versus homogeneous waterbath heating at $43^{\circ} \mathrm{C}$ (A). Within the first $60 \mathrm{~min} \mathrm{MFH}$ has a larger efficacy due to additional effects of intracellular excited ferrofluid particles. At 120 min this effect tends to zero. At maximum, the difference of the survival fractions between both heating methods is nearly 3 -fold. (B) After a $45^{\circ} \mathrm{C}$ hyperthermia, this effect is again 3 -fold, but only within the first $5 \mathrm{~min}$. At $25 \mathrm{~min}$ already the gain of intracellular MFH is zero in comparison to waterbath hyperthermia.

knowledge is related to the phagocytosis of different polymer beads into macrophages, but less into malignant cells. Much work has been done by Kreuter et al. [17] upon the strategies to manipulate nanoparticle surfaces to enhance blood half time and targeting to certain cells and tissues. However, most of the papers deal with chemical modifications, e.g. functionalized surfaces or surfactants to circumvent the activity of the reticuloendothelial system (RES), which normally captures all particles of any size and structure out of the blood stream into liver and spleen. From the present data, a large difference of uptake between different particles and cell types has been demonstrated but interaction with the RES has not been tested, so far.
REM and TEM analysis have indicated, that differential endocytosis is obviously associated with the adhesion capability of the particles to the cell surface. In those cell lines, which had a minor amount of particles on the outer membrane (Fig. 7B) in fact had a minor particle uptake (Fig. 3A). In the case of RuSi-RS1 the opposite was true in terms of \# BU48 uptake: many particles on the cell surface (Fig. 8C) are associated with large intracellular uptake (Fig. 3B). Besides the chemical structure, the only two known different parameters between both particle types are the hydrodynamic size and the surface charge, which may be relevant to explain this differential particle adhesion and internalization capability (Table 1). Since \#BU48 has a nearly 4-fold lower particle size but a very high surface charge due to linkage of many aminogroups to the silan shell, electrostatic binding may be one explanation of the observed adhesion. The counterpart of the large positive particle surface charge under physiological $\mathrm{pH}$ may be conjugate proteins in the plasma membrane, which are supposed to present more negatively charged amino acids onto the surface of the cell.

Especially the TEM data indicate a further aspect of differential endocytosis, which might be the division activity or doubling time of the cell. Fast dividing cells, like fibroblasts and malignant cells exhibit rather large uptake, whereas slower dividing cells either malignant or normal like WiDr and HCN do not take up much of both particle types. In the case of malignant cells the relevance of this parameter is supported by the known de-differentiation of highgrade malignancies, which leads to a loss of specific cell functions and a decrease of membrane specificity. Additionally, most of the actively growing tumor cells have often bad physiological conditions in their environment or micromilieu, due to hypoxia. Especially when chaotic vascularization of a tumor collapses after a therapeutic intervention, nutrient supply is low. Then it might be an advantage for tumor cells to use their unspecific endocytosis capability to increase the probability of a random nutrient ingestion, of which single components normally are recognized by specific receptors (e.g. free glucose) but are not available at the time.

How many particles each individual tumor cell really takes up cannot be determined with the bulk 
experiments performed, so far. Therefore it might be possible, that some cells at least in vitro take up only a few or none of the particles whereas others take up a large portion, which altogether yields the uptake values shown in Figs. 1-4. From the magnet experiments we know, that this low-uptake fraction is with BT20 cells around $10 \%$. Why some clonogenic cells of a continuously dividing culture express such a different endocytosis activity, is not known so far. As is with radiation, drug and hyperthermia cell sensitivity, different sub-populations or a small portion of not actively dividing (G0) cells may be one of the reasons for this different behavior.

If tumor cells have taken up ferrofluid particles in an amount of at least $200 \mathrm{pg} / \mathrm{cell}$ (Fig. 3B), inactivation is possible by an externally applied AC magnetic field without particle deposit outside the cells. This situation might occur in vivo by the activity of the RES, which normally captures any particles out of lymph capillaries and the blood stream. Hence, only the ingested or paracellularly adhesive particles would contribute to heat-induced cell inactivation. In addition to this fascinating "remote killing" of cancer cells, Fig. 12A and Fig. 12B demonstrate, that heat is not the only effect of intracellular MFH. An additional effect is induced within the first $60 \mathrm{~min}$, which further decreases the survival fraction in comparison to homogeneous waterbath heating.

Random distribution of phagosomes might also include heating of particles, which might be in the neighborhood to heat sensitive organelles, like the nucleus or plasma membrane or any of the signal transduction molecules within the cell. According to our electron microscopic findings, it is necrosis not apoptosis, which kill the cells. No apoptotic bodies or typical chromosome condensation was observed. Instead, vacuolization and increase of the cell body was obtained.

Intracellular MFH is no longer a matter of faith and further studies will demonstrate its potential in terms of cancer therapy or in any other medical intervention not taken into account, so far.

\section{Acknowledgements}

This project is supported by the Deutsche Forschungsgemeinschaft (DFG, SFB 273), the
Lieselotte Beutel Stiftung Berlin and the Sparkassen Stiftung Berlin. We also wish to thank the Institute of Pathology of the University Clinic Charite, Dpt. Of Electron Microscopy, namely Prof. Schnoy, for valuable assistance and many fruitful discussions about the interpretation of all the electron microscopy data.

\section{References}

[1] A. Jordan, P. Wust, R. Scholz et al., in: U. Häfeli, W. Schütt, J. Teller, M. Zborowski (Eds.), Scientific and Clinical Applications of Magnetic Carriers, Plenum, New York, 1997.

[2] R.T. Gordon, J.R. Hines, D. Gordon, Med. Hypothesis 5 (1979) 83.

[3] D.C.F. Chan, D.B. Kirpotin, P.A. Bunn, J. Magn. Magn. Mater. 122 (1993) 374.

[4] D.C.F. Chan, D.B. Kirpotin, A. Baerjee et al., Proceedings of the 6th International Congress on Hyperthermic Oncology (ICHO), 1992, p. 367.

[5] A. Jordan, P. Wust, R. Scholz et al., Int. J. Hyperthermia 12 (1996) 705.

[6] A. Jordan, P. Wust, H. Fähling et al., Proceedings of the 6th International Congress on Hyperthermic Oncology (ICHO), 1992, p. 138.

[7] A. Jordan, P. Wust, H. Fähling et al., Proceedings of the 42nd Scientific Meeting of the Radiation Research Society and the 14th Annual Meeting of the North American Hyperthermia Society, 1994, p. 117.

[8] A. Jordan, R. Scholz, N. Schnoy et al., Europ. J. Cell Biol. 47 (Suppl.) (1997) 32.

[9] A. Jordan, R. Scholz, P. Wust et al., Proceedings of the 17th Annual Meeting of the European Society for Hyperthermic Oncology (ESHO), 1998, p. 15.

[10] A. Jordan, R. Scholz, P. Wust et al., Proceedings of the 8th International Conference on Magnetic Fluids (ICMF8), 1998, p. 17.

[11] J.C. Bacri, M.F. DaSilva, R. Perzynski et al., in: U. Häfeli, W. Schütt, J. Teller, M. Zborowski (Eds.), Scientific and Clinical Applications of Magnetic Carriers, Plenum, New York, 1997.

[12] A. Halbreich, M.F. DaSilva, J.C. Bacri et al., Proceedings of the 2nd International Conference on the Scientific and Clinical Applications of Magnetic Carriers, 1998, p. 30.

[13] A.R. Muir, L. Goldberg, Q. J. Exp. Physiol. 66 (1961) 289.

[14] S. Saini, D.D. Stark et al., Radiology 162 (1987) 211.

[15] T. Yeh, W. Zhang et al., Magnet. Reson. Med. 30 (1993) 617.

[16] A. Jordan, R. Scholz, J. Schüler et al., Int. J. Hyperthermia 13 (1997) 83.

[17] J. Kreuter, Eur. J. Drug Metab. Pharmacokinet. 19 (1994) 253. 